\title{
Prenatal Diagnosis, Where and How: No Way Out?
}

\author{
${ }^{1}$ Franco Borruto, ${ }^{2}$ Alain Treisser, ${ }^{3}$ Ciro Comparetto
}

\section{ABSTRACT}

Prenatal diagnosis is the branch of medicine and in particular of obstetrics, that studies and applies the techniques that reveal the normality or the presence of diseases of various kinds, in the fetus. All the techniques of prenatal diagnosis are performed during pregnancy and may be invasive or less. Among the best known, amniocentesis is the most exploited technique nowadays to highlight the possible presence of chromosomal disorders in the fetus, but also infections and genetic diseases such as thalassemia, cystic fibrosis, hemophilia, spina bifida, albinism. Amniocentesis consists of taking an amniotic fluid sample which is then analyzed. Fetal cells suspended in the withdrawn liquid allow us to reconstruct the chromosome map of the fetus and then to confirm or not its normality. Genetic testing, however, are not able to recognize the physical or mental characteristics of the unborn child which are the result of the interaction between multiple genes and the environment. Amniotic fluid makes possible to perform other types of analysis, more or less complex, and it is also possible to store the amniotic stem cells. Similar to amniocentesis as a principle but different as a technique, is chorionic villus sampling (CVS), in which the cells can be put in culture to show their normality, but they are cells taken outside from the gestational chamber (chorionic villi). These are invasive techniques (the fluid is taken by puncture in both cases), but there are also noninvasive techniques. The development of ultrasound, for example, has made it possible to develop some highly sensitive diagnostic techniques, such as the first trimester combined test [bitest and nuchal translucency (NT)], the 'quadruple' test, and lately the SCA test in the second trimester, all based on the ultrasound measurement of anatomical and functional parameters of the fetus and on the results of blood tests. These are all screening tests, then they do not give a definite answer but they have a statistical value (very accurate) that can direct toward diagnostic tests. Recently, an extremely sensitive test for the most common aneuploidies and in particular Down syndrome has been proposed to be performed on maternal blood. This test (called fetal DNA testing) is based on the count of fragments of specific chromosomes ( 21 in the case of Down syndrome) in maternal blood. Although not belonging to diagnostic tests but to probabilistic ones, this test is absolutely the most accurate so far available, with values around $99.99 \%$ sensitivity and $0.2 \%$ false positives. Also ultrasound in the second trimester of pregnancy (also called morphological ultrasound) that can detect any malformation or fetal abnormality and fetal echocardiography, which analyzes

\footnotetext{
${ }^{1}$ Professor, ${ }^{2} \mathrm{Head},{ }^{3}$ Specialist

1,2Division of Obstetrics and Gynecology, Princess Grace Hospital Monaco, Monaco

${ }^{3}$ Division of Obstetrics and Gynecology, City Hospital Prato, Italy

Corresponding Author: Ciro Comparetto, Specialist, Division of Obstetrics and Gynecology, City Hospital, Azienda USL 4 Prato, Italy, e-mail: cicomp@tin.it
}

sonographically the fetal heart not only anatomically but also from the dynamic-functional point of view, may be considered methods of prenatal diagnosis. This technique cannot identify genetic diseases.

Keywords: Amniocentesis, Cell-free fetal DNA, First trimester screening, Pregnancy, Prenatal diagnosis.

How to cite this article: Borruto F, Treisser A, Comparetto C. Prenatal Diagnosis, Where and How: No Way Out? Donald School J Ultrasound Obstet Gynecol 2014;8(3):293-310.

Source of support: Nil

Conflict of interest: None

\section{INTRODUCTION}

The phenomenal developments in molecular genetics and technological refinements which have occurred over the past decades have revolutionized the area of prenatal genetics. State-of-the-art care commences with comprehensive preconceptional counseling. Prenatal diagnosis is now feasible from the moment of conception onward. Imaging techniques have allowed noninvasive diagnosis while minimally invasive techniques concentrate on sampling maternal blood for fetal cells or markers of feto-placental metabolism. Invasive techniques have been rapidly expanding and becoming safer, comprising of chorionic villus sampling (CVS), early amniocentesis, midtrimester amniocentesis, as well as very early fetoscopy and umbilical vein sampling. ${ }^{1}$ Advances in prenatal diagnostic techniques allow for earlier, more rapid and more effective detection of congenital disorders. Recent advances in noninvasive detection methods, such as fetal ultrasound and the isolation of fetal cells in the maternal circulation, allow the intrauterine diagnosis of congenital infections and chromosomal and Mendelian disorders, as well as hematologic disorders. ${ }^{2}$

Many disorders have already been successfully diagnosed or excluded in utero. We currently have the potential to diagnose a number of others for which the opportunity has not yet arisen. If a biochemical, morphologic, chromosomal, or deoxyribonucleic acid (DNA) alteration is known for a specific condition and is likely to be expressed in one of the fetal tissues or secretions, attempt at prenatal diagnosis is reasonable. Our ability to detect the inherited disorders in utero will continue to improve both in the number of specific disorders successfully diagnosed or excluded and in the increasingly earlier stages of pregnancy at which the disorder can be detected. Advances in instrumentation have decreased the risk of the invasive methods of prenatal 
diagnosis, and improvement in noninvasive methods, such as maternal serum screening (MSS), may eliminate the need for invasive procedures altogether. Detection of useful DNA polymorphisms linked to genes for specific diseases and development of specific gene probes have improved the accuracy of diagnosis and reduced the need for specific fetal tissues. The entire genome of an individual is present in each cell, even though a specific gene product may not be expressed in that cell. Thus, DNA restriction endonuclease studies can be performed on amniotic fluid cells, chorionic villi, fetal cells in maternal circulation and fetal tissues with equal facility. The usefulness of prenatal diagnosis will always be limited by the ability to detect pregnancies at risk. If carrier detection is unavailable, the only way to identify couples at risk for offspring with an autosomal recessive condition is by the birth of an affected child. For autosomal dominant and X-linked recessive and dominant conditions, new mutations will continue to occur. As mentioned previously, screening of all pregnancies for all defects is not possible now and is unlikely ever to be feasible, either economically or technically. The reliability of prenatal diagnosis will continue to depend upon accurate diagnosis in the index case and upon the availability of a specific and sensitive test (or tests), with no overlap in values between heterozygotes and homozygotes for autosomal recessive conditions or between normal and affected fetuses with autosomal dominant and X-linked recessive disorders. Correct interpretation of test results is subject to experience, recognition of artifact, and variation in the expression of a given disorder in utero. ${ }^{3}$

Prenatal diagnosis of aneuploidy and single-gene disorders is usually performed by collecting fetal samples through amniocentesis or CVS. However, these invasive procedures are associated with some degree of risk to the fetus and/or mother. Therefore, in recent years, considerable effort has been made to develop noninvasive prenatal testing (NIPT) and noninvasive prenatal diagnosis (NIPD). One potential noninvasive approach involves analysis of cellfree fetal DNA (cffDNA) in maternal plasma or serum. Another approach utilizes fetal cells within the maternal circulation as a source of fetal DNA. ${ }^{4}$ In fact, fetal cells and cffDNA can be found circulating in maternal blood. Fetal cells recovered from maternal blood provide the only source of pure fetal DNA for NIPT. Fetal nucleated erythrocytes are considered the most suitable maternallycirculating fetal cells for this purpose, because they are not commonly found in the peripheral blood of healthy adults and are most abundant in the fetus during early gestation. Because fetal cells in maternal blood are extremely rare, a definitive separation method has not yet been established. Fetal nucleated erythrocytes can be enriched from maternal blood via fluorescence- or magnetic-activated cell sorting (MACS), density gradients, immuno-magnetic beads, or micromanipulation. Fetal cells are identified by Giemsa staining, hybridization with Y-chromosome specific probes, polymerase chain reaction (PCR)-detection of a specific paternal allele, or immunostaining for fetal cell antigens. Amplification of fetal DNA sequences by primer extension preamplification (PEP) and PCR has allowed prenatal screening for Duchenne muscular dystrophy and the fetal Rhesus (RhD) blood type. Sequence-specific hybridization has been used to detect sickle cell anemia and beta-thalassemia prenatally in heterozygous carriers of these disorders. ${ }^{5}$ Thus, at the present time, fetal gender and fetal $\mathrm{RhD}$ blood type within $\mathrm{RhD}$-negative pregnant women can be reliably determined through analysis of maternal plasma. Furthermore, genetic alterations can be diagnosed in the maternal plasma, when the mother does not have the alterations. However, the diagnosis of maternally inherited genetic disease and aneuploidy is limited using this approach. ${ }^{4}$ The use of cffDNA in maternal plasma for the diagnosis of single-gene disorders is limited to disorders caused by a paternally inherited gene or a mutation that can be distinguished from the maternally inherited counterpart. At present, fetal gender can be determined from maternal plasma. When a pregnant woman is a heterozygous carrier of an X-linked disorder, the determination of fetal gender is clinically very informative for first-step screening to avoid invasive amniocentesis. Noninvasive prenatal diagnosis of genetic disorders should be applied to pregnant women with a definite risk for a specific single-gene disorder. ${ }^{5}$ Noninvasive prenatal diagnosis through examination of intact fetal cells circulating within maternal blood can be used to diagnose a full range of genetic disorders. Since, only a limited number of fetal cells circulate within maternal blood, the above cited procedures to enrich the cells and enable single cell analysis with high sensitivity are required. Recently, separation methods, including a lectin-based method and autoimage analyzing, have been developed, which have improved the sensitivity of genetic analysis. This progress has supported the possibility of NIPD of genetic disorders. ${ }^{4}$

\section{Historical Notes}

Prenatal diagnosis of fetal genetic conditions is a standard part of modern obstetric care. Many of the current methods rely on invasive methods and are associated with an inherent risk of fetal loss. Consequently, there has been a long-term goal for development of NIPD. The first report of the occurrence of fetal cells in maternal circulation dates back to 1893 , when the German pathologist Schmorl identified trophoblast cells in the lungs of women who had died from eclampsia. Till recently, however, the existence of 
fetal cells in maternal blood was a matter of considerable debate. The main reason for this dispute was the inability to successfully and reliably enrich for these cells, which has also hindered their clinical use. In the meantime, this issue has been addressed and both the fetal aneuploidies and single gene defects can now be detected in a noninvasive manner using fetal cells enriched from maternal blood. ${ }^{6}$ Since, the discovery of circulating nucleic acids in plasma in 1948, many diagnostic applications have emerged. For example, diagnostic and prognostic potentials of circulating tumor-derived DNA have been demonstrated for many types of cancer. The parallel development of fetal-derived DNA detection in maternal plasma has opened up the possibility of NIPT and monitoring of many pregnancy-associated disorders. In this regard, noninvasive fetal $\mathrm{RhD}$ blood group genotyping has already been translated into clinical practice. Other applications of circulating DNA in traumatology and transplant monitoring have also been reported. The more recent discoveries of circulating tumor-derived ribonucleic acid (RNA) and fetal-derived RNA have proven to be equally important as their DNA counterparts. Successful prenatal diagnosis of Down syndrome (DS) by fetal RNA analysis has recently been reported. However, the definite origin and release mechanisms of circulating nucleic acids have remained incompletely understood, with cell death being suggested to be associated with such nucleic acid release. ${ }^{7}$

Pregnancy screening for fetal aneuploidy (e.g. DS and trisomy 18) started in the mid 1960s, using maternal age as the screening test. The research into noninvasive and invasive prenatal diagnostic techniques developed almost in parallel. On the one hand, the need was arising to ensure the birth of normal progeny in all cases, while on the other hand, it was not possible to eliminate the not insignificant abortion risks of invasive diagnosis. One of the first researchers in the noninvasive field was Adinolfi who published the earliest data in 1974 on the possibility of detecting three types of fetal cells in the maternal circulation using flow cytometry. Adinolfi suggested the possibility of using fetal cells present in the maternal circulation for prenatal diagnosis of chromosome or biochemical anomalies. Cells are also present in the endocervical canal where from the 8th week of pregnancy, it is only possible to obtain trophoblast cells. This technique has since been abandoned due to the scarcity of cellular material available, the greater risk of contamination by cells of maternal origin, and also because the recovery of the cells is unpredictable, despite their potential use for the early noninvasive diagnosis of sex. ${ }^{8}$ Over the past 40 years, much effort has been spent on developing NIPD. There has recently been an upsurge of interest in the analysis of circulating nucleic acids (DNA and/or RNA) in blood plasma or serum as a clinical diagnostic tool. Occasional earlier reports suggested the existence of circulating nucleic acids, but the potential clinical implication was not realized until 1996, when DNA with tumor-specific characteristics was demonstrated in the plasma/serum of cancer patients. This finding opened up possibilities for noninvasive cancer diagnosis. Potential applications have been reported in cancer diagnosis, prenatal diagnosis, transplantation and traumatology. Some of the findings are on the verge of being translated into clinical use. DNA is also now being sought in other body fluids, such as urine. ${ }^{9}$

In 1997, the presence of circulating fetal DNA in maternal plasma and serum was first discovered by Lo et al through the detection of Y-chromosome-specific sequences in the plasma of women conceived with male fetuses and has become a useful tool for prenatal diagnosis in less than 5 years. This discovery has opened up new possibilities in the development of NIPT by a source of fetal genetic material that could be conveniently accessible simply through the collection of a maternal peripheral blood sample. It has been shown that cffDNA analysis could offer highly accurate assessment of fetal genotype and chromosomal make up for some applications. Thus, cffDNA analysis has been incorporated as a part of prenatal screening programs for the management of fetal RhD blood genotyping to prevent incompatibility, prenatal diagnosis of sex-linked and sex-associated disorders, paternally inherited genetic diseases, as well as the prenatal detection of DS, and is a viable indicator of predisposition to certain obstetric complications (e.g. pre-eclampsia). More recently, there have been significant new developments with expanding number of potential applications. ${ }^{10,11}$ Since 1997, in fact, these developments have been translated into many novel genetic, epigenetic, and gene-expression markers, and are expected to have a fundamental impact on the future practice of prenatal diagnosis. ${ }^{12}$ Management of pregnancies at risk of an X-linked Mendelian disorder has changed thanks to the noninvasive fetal sex assessment. As for other Mendelian disorders, until recently, their study was limited to those cases paternally inherited. Nevertheless, the new emerging technologies are also opening the scope to maternally inherited disorders. ${ }^{13}$

Since 1997, many studies have examined the accuracy of prenatal fetal sex determination using cffDNA, particularly for pregnancies at risk of an X-linked condition. To evaluate the use of cffDNA for prenatal determination (diagnosis) of fetal sex overall mean sensitivity was 96.6\% [95\% confidence interval $(\mathrm{CI})=95.2-97.7]$ and mean specificity was $98.9 \%$ (95\% CI = 98.1-99.4). These results vary very little with trimester or week of testing, indicating that the performance of the test is reliably high. Thus, fetal sex can be determined with a high level of accuracy by analyzing 
cffDNA. Using cffDNA in prenatal diagnosis to replace or complement existing invasive methods can remove or reduce the risk of miscarriage. Future work should concentrate on the economic and ethical considerations of implementing an early noninvasive test for fetal sex. ${ }^{14,15}$ The use of circulating cffDNA for the NIPT of fetal chromosomal aneuploidies is challenging as fetal DNA represents a minor fraction of maternal plasma DNA. In 2007, it was shown that single molecule counting methods would allow the detection of the presence of a trisomic fetus, as long as enough molecules were counted. With the advent of massively parallel sequencing (MPS), millions or billions of DNA molecules can be readily counted. Using MPS, fetal trisomies 21, 13 and 18 have been detected from maternal plasma. Recently, large-scale clinical studies have validated the robustness of this approach for the prenatal detection of fetal chromosomal aneuploidies. A proof-of-concept study has also shown that a genome-wide genetic and mutational map of a fetus can be constructed from the maternal plasma DNA sequencing data. These developments suggest that the analysis of fetal DNA in maternal plasma would play an increasingly important role in future obstetrics practice. ${ }^{16}$

Post-genomics technologies that explore the proteins (proteomics) and transcripts (transcriptomics) released by the placenta into the maternal circulation offer new opportunities to identify genes and their protein products that are key diagnostic markers of disease (in particular DS), and might replace the current screening markers in use for prediction of risk of DS. In the ideal situation, these markers are sufficiently diagnostic not to require invasive sampling of fetal genetic material. Post-genomics techniques might also offer better opportunities for defining fetal cell-specific markers that might enhance their isolation from maternal blood samples. Progresses in these studies are particularly those funded by the special noninvasive advances in fetal and neonatal evaluation (SAFE) network of excellence (NoE). ${ }^{17}$ SAFE is a European Union Framework, NoE which facilitates the implementation of NIPD for single gene disorders, fetal RhD typing, aneuploidy and pregnancy complications. ${ }^{18}$ The SAFE project was set up to implement routine, cost-effective NIPD and neonatal screening through the creation of long-term partnerships within and beyond the European community and has played a major role in the standardization of noninvasive RhD genotyping. Other research using cffDNA has focused on the amount of cffDNA present in the maternal circulation, with a view to pre-empting various complications of pregnancy. One of the key areas of interest in the noninvasive arena is the prenatal detection of aneuploidy pregnancies, particularly DS. Owing to the high maternal DNA background, detection of cffDNA from maternal plasma is very difficult. Consequently, research in this area is now more focused on cffRNA to produce new biomarkers. ${ }^{19}$

Proteomics-based identification of biomarkers for fetal abnormalities in maternal plasma, amniotic fluid, and reproductive fluids has made significant progress in the past 10 years. This is attributed mainly to advances in various technology platforms associated with mass spectrometrybased techniques. As these techniques are highly sensitive and require only small quantities of body fluids, it is hoped that they will pave the way for the development of effective noninvasive approaches, without subjecting the developing fetus to the same degree of harm as current invasive procedures (e.g. amniocentesis). It is possible that these developments will include same-day analyses, thereby permitting rapid intervention when necessary. To date, a host of body fluids, such as maternal serum and plasma, amniotic fluid, cervical fluid, vaginal fluid, urine, saliva, or fetal material, such as placental trophoblast, fetal membranes, or cord blood, have been used successfully in the quest to develop markers for a number of pregnancyrelated pathologies. The emergence of proteomics has come as a major platform technology in studying various types of fetal conditions and developing markers for pregnancyrelated disorders, such fetal aneuploidy, preterm birth, pre-eclampsia, intra-amniotic infection and fetal stress. ${ }^{20}$ Comparisons of proteomes of normal fluids with those from aneuploidy pregnancies have revealed a host of candidate markers that still need to be verified. In parallel with proteomics, there is interest in other emerging techniques, such as RNA-single nucleotide polymorphism (SNP) analysis or quantitation of fetal DNA by shotgun sequencing. Although these genomic techniques hold much promise, discovery of additional markers via quantitative proteomic comparisons could drastically improve current conventional screening at reasonable cost. Proteomics-based biomarker discovery is applicable to detection of not just aneuploidies, but also other pregnancy-related diseases. Should the development of these markers be successful, then it is to be envisaged that proteomic approaches will become standard of care for a number of disease conditions associated with feto-maternal health. ${ }^{21}$

\section{Prenatal Screening and Diagnosis of Down Syndrome}

Down syndrome occurs when a person has three copies of chromosome 21 (or the specific area of chromosome 21 implicated in causing DS) rather than two (trisomy 21). It is the commonest congenital cause of mental retardation. Noninvasive screening based on biochemical analysis of maternal serum or urine, or fetal ultrasound measurements, allows estimates of the risk of a pregnancy being affected 
and provides information to guide decisions about definitive testing. ${ }^{22}$ Two-thirds of the patients with DS are born by women below 35 years of age. An extension of invasive prenatal diagnosis to these women is problematical due to the operative risks and the relatively high costs. Therefore, noninvasive screening methods are sought, apt to identify groups at high risk, such as biochemical screening methods applied at 16 weeks of pregnancy (triple test), the first trimester tests and ultrasound screening at 10 to 12 weeks. A large fluid cushion over most of the back was documented not only in most cases of trisomy 21 but in trisomies 18 and 13 and in Turner syndrome (TS) as well. Only few chromosomally normal fetuses with the same peculiarity were observed. Systematic first trimester screening for nuchal fluid accumulation seems to be a recommendable method for the detection of chromosome anomalies. It compares favorably with methods of MSS performed at 16 to 18 weeks which require a manyfold higher number of invasive procedures. ${ }^{23}$ Prenatal diagnosis of trisomy 21 currently relies on assessment of risk followed by invasive testing in 5\% of pregnancies at the highest estimated risk. Selection of the high-risk group by a combination of maternal age and second-trimester maternal serum biochemistry gives a detection rate of about $60 \%$. Assessment of risk by a combination of maternal age and fetal nuchal translucency (NT) thickness, measured by ultrasonography at 10 to 14 weeks of gestation, has been investigated. Selection of the high-risk group for invasive testing by this method allows the detection of about $80 \%$ of affected pregnancies. However, even this method of risk assessment requires about 30 invasive tests for identification of one affected fetus. ${ }^{24,25}$

Studies evaluating tests of maternal serum in women at 14 to 24 weeks of gestation for DS, compared with a reference standard, either chromosomal verification or macroscopic postnatal inspection, have been made. Data were extracted as test positive/test negative results for Down's and nonDown's pregnancies allowing estimation of detection rates (sensitivity) and false positive rates (1-specificity). Twelve different tests have been matched with maternal age: alpha-fetoprotein (AFP), unconjugated estriol (uE3), total human chorionic gonadotrophin (hCG), free $\beta-\mathrm{hCG}$, free $\alpha$-hCG, inhibin A, specificity protein 2 (SP2), cancer antigen 125 or carbohydrate antigen 125 (CA125), troponin, pregnancy-associated plasma protein A (PAPP-A), placental growth factor (PGF), and proform of eosinophil major basic protein (ProMBP). Meta-analysis of 12 best performing or frequently evaluated test combinations showed double and triple tests (involving AFP, uE3, total hCG, free $\beta$-hCG) significantly outperform individual markers, detecting 6 to 7 out of every $10 \mathrm{DS}$ pregnancies at a $5 \%$ false positive rate. Tests additionally involving inhibin performed best
(8 out of every 10 DS pregnancies) but were not shown to be significantly better than standard triple tests in direct comparisons. Significantly lower sensitivity occurred in women over the age of 35 years. Women who miscarried in the over 35 group were more likely to have been offered an invasive test to verify a negative screening results, whereas those under 35 were usually not offered invasive testing for a negative screening result. Pregnancy loss in women under 35 therefore leads to under ascertainment of screening results, potentially missing a proportion of affected pregnancies and affecting the accuracy of the sensitivity. Tests involving two or more markers in combination with maternal age are significantly more sensitive than those involving one marker. The value of combining four or more tests or including inhibin have not been proven to show statistically significant improvement. Further study is required to investigate reduced test performance in women aged over 35 and the impact of differential pregnancy loss on study findings. ${ }^{22}$

Fetal ultrasound screening has become routine practice in many Western countries. During the last two decades, such screening has led to frequent situations characterized by clinical uncertainty due to the disclosure of soft markers in the unborn child. Soft markers are minor anatomical variations indicating a somewhat increased likelihood that the fetus has a chromosomal aberration, most frequently trisomy 21. An analysis of the literature makes evident that many ultrasound examiners have counseled individual pregnant women on the basis of insufficient data. Moral dilemmas have thus emerged as a direct result of advancing medical technology, and healthy fetal lives prove to have been lost due to invasive diagnostic testing aimed at resolving clinical uncertainty. Ultrasound examiners have warned against a policy of disclosing all findings of soft markers to expectant parents, but no exploration of experiential aspects linked to the disclosure of fetal soft markers has yet been published in the medical literature. The emotional reactions of mothers are important to consider given their potential impact on the biological development of the fetus. ${ }^{26-28}$ Assisted reproductive techniques (ART) have increased the number of pregnant women beyond the age of 35 years and the incidence of multiple pregnancies. Specific problems are encountered when noninvasive screening methods are applied for pregnancies achieved by ART. Overall, more women with assisted reproduction singleton pregnancies are found to be false-positive for DS. This is because standard screening algorithms include maternal age. In addition, midtrimester MSS is associated with a higher false-positive rate. This is due to changes in the fetoplacental endocrinological metabolism in pregnancies achieved by ART. Ultrasound screening of DS by means of NT measurements at 10 to 14 weeks is associated with a lower false-positive rate than 
mid-trimester serum screening. The lowest false-positive rates reported in singleton pregnancies are observed when serum and NT screening are combined at 10 to 14 weeks. In multiple pregnancies, mid-trimester MSS is of limited clinical value. Nuchal translucency measurement is among the best available and is the most efficient screening method for multiple pregnancies. This sonographical method for screening enables specific identification of those fetuses at high risk of DS and other anomalies, and thus contributes to a better outcome. Therefore, it should be systematically performed before any fetal reduction in high-order multiple pregnancies is planned. ${ }^{29}$

As we have seen before, both intact fetal cells as well as cffDNA are present in the maternal circulation and can be recovered for NIPT. Although methods for enrichment and isolation of rare intact fetal cells have been challenging, diagnosis of fetal chromosomal aneuploidy including trisomy 21 in first- and second-trimester pregnancies has been achieved with a 50 to $75 \%$ detection rate. Similarly, cffDNA can be reliably recovered from maternal plasma and assessed by quantitative PCR to detect fetal trisomy 21 and paternally derived single gene mutations. Real-time PCR assays are robust in detecting low-level fetal DNA concentrations, with sensitivity of approximately 95 to $100 \%$ and specificity near $100 \%$. Comparing intact fetal cell $v s$ cffDNA methods for noninvasive prenatal screening for fetal chromosomal aneuploidy reveals that the latter is at least four times more sensitive. These preliminary results do not support a relationship between frequency of intact fetal cells and concentration of cffDNA. The above results imply that the concentration of fetal DNA in maternal plasma may not be dependent on circulating intact fetal cells but rather be a product of growth and cellular turnover during embryonic or fetal development. ${ }^{30}$ Since, the existence of cffDNA in maternal circulation was discovered, it has been identified as a promising source of fetal genetic material in the development of reliable methods for NIDP of fetal trisomy 21. Currently, a prenatal diagnosis of fetal trisomy 21 is achieved through invasive techniques, such as CVS or amniocentesis. However, such invasive diagnostic tests are expensive, require expert technicians, and have a miscarriage risk approximately $1 \%$. Therefore, NIPT using cffDNA in the detection of fetal trisomy 21 is significant in prenatal care. Recently, the application of new techniques using single-molecular counting methods and the development of fetal-specific epigenetic markers has opened up new possibilities in the NIPD of fetal trisomy 21 using cffDNA. These new technologies will facilitate safer, more sensitive and accurate prenatal tests in the near future. ${ }^{31}$

\section{Prenatal Diagnosis by Transcervical Recovery of Placental Cells}

One of the investigations that have been used with the aim of performing prenatal diagnosis of inherited disorders by noninvasive or minimally invasive techniques is the identification and isolation of fetal trophoblastic cellular elements shed into the uterine cavity and the endocervical canal. Methods have been employed for the collection of the transcervical samples at an early stage of gestation and techniques use the identification of fetal cells within endocervical cells for the detection of fetal chromosomal disorders by fluorescent in situ hybridization (FISH) and for performing prenatal diagnosis of fetal RhD phenotypes. Recent investigations have also shown that, after the isolation of trophoblastic cells from maternal contaminants by micromanipulation, transcervical samples can be employed for the prenatal diagnosis of single gene defects, such as those causing thalassemia and sickle cell anemia. ${ }^{32}$ Efficient recovery of placental cells (and their subsequent characterization) has been obtained from the lower uterine pole by transcervical intrauterine flushing [using $0.15 \mathrm{M}$ sodium chloride $(\mathrm{NaCl})$ ] or mucus aspiration. Embryo transfer (ET) catheters can be used in both procedures. Fetal sexing can be achieved by gene amplification of Y-specific DNA sequences (Y-PCR), and by ISH (bright-field and fluorescence) to the Y-chromosome. Gender-independent tests for fetal cells utilize immunocytochemistry with trophoblast-specific antibodies and dual immunocytochemistry/ISH, where appropriate. Since, Y-derived DNA can be detected in $>50 \%$ of flushings and aspirations, and gender-independent evidence for placental cells can be obtained, regardless of fetal sex, most or all of these samples contain placental cells, including trophoblasts and naked nuclei. Transcervical placental cell recovery is a potentially valuable alternative to more invasive methods of aneuploid detection which require amniocentesis and CVS, provided its level of accuracy and, above all, safety can be evaluated. Although the present results are promising, further investigations are required to demonstrate the feasibility of performing accurate diagnosis of fetal diseases by this minimally invasive approach in all transcervical samples retrieved at an early stage of gestation. $^{33,34}$

\section{Prenatal Diagnosis by Detection of Fetal Cells in Maternal Circulation}

The existence of fetal cells in the blood of pregnant women is now well-established. Recognizing these cells with specific antibodies and isolating them with fluorescent or magnetic systems have been the subject of numerous 
studies. ${ }^{35}$ When the gestation is normal, fetal cells are low in number. Complications of pregnancy, such as pre-eclampsia, or fetal cytogenetic abnormalities, such as DS, increase fetomaternal transfusion. The isolation of fetal cells from maternal blood is currently under active investigation as a NIPD method. The fetal cells that are most commonly used for noninvasive genetic diagnosis, the nucleated erythrocyte and the trophoblast, are highly differentiated and do not persist postpartum. In the context of studying fetal cells in maternal blood, it was discovered that fetal progenitor cells originating from a prior pregnancy could also be detected. This led to the appreciation that unlike fetal DNA in plasma, which is cleared almost immediately following delivery, fetal cells persist for decades postpartum. Following pregnancy, labor, and delivery, a woman becomes a chimera. Transfused fetal stem and progenitor cells appear to be capable of further differentiation and migration to maternal organs. A further research agenda is needed to explore the newly appreciated phenomenon of bidirectional fetomaternal cell trafficking. Any consideration of the fetus as a patient must also consider the fetus as a potential source of therapeutic stem cells for the mother. ${ }^{36}$ Stem cells have been isolated at all stages of development from the early developing embryo to the postreproductive adult organism. However, the fetal environment is unique as it is the only time in ontogeny that there is migration of stem cells in large numbers into different organ compartments. While fetal neural and hemopoietic stem cells (HSC) have been well characterized, only recently have mesenchymal stem cells (MSC) from the human fetus been isolated and evaluated. Some groups have characterized in human fetal blood, liver, and bone marrow a population of nonhemopoietic, nonendothelial cells with an immunophenotype similar to adult bone marrowderived MSC. These cells, human fetal MSC (hfMSC), are true multipotent stem cells with greater self-renewal and differentiation capacity than their adult counterparts. They circulate in first trimester fetal blood and have been found to traffic into the maternal circulation, engrafting in bone marrow, where they remain microchimeric for decades after pregnancy. Though fetal microchimerism has been implicated in the pathogenesis of autoimmune disease, the biological role of hfMSC microchimerism is unknown. Potential downstream applications of hfMSC include their use as a target cell for NIPD from maternal blood, and for fetal cellular and gene therapy. Using hfMSC in fetal therapy offers the theoretical advantages of avoidance of immune rejection, increased engraftment, and treatment before disease pathology sets in. Aside from allogeneic hfMSC in utero transplantation, the use of autologous hfMSC has been brought a step forward with the development of early blood sampling techniques, efficient viral transduction and clonal expansion. Work is ongoing to determine hfMSC fate post-transplantation in murine models of genetic disease. ${ }^{37}$

Despite intensive investigation, a satisfactory, clinically acceptable, reproducible, reliable, and noninvasive method based on retrieval of rare fetal cells from the maternal circulation has not yet emerged. Several cell types have been targeted to this end, mostly fetal nucleated erythrocytes, cluster D (CD) $34^{+}$hematopoietic progenitors, and trophoblasts. Although these cell types have been unequivocally proven to be present in the maternal circulation, each bears a significant disadvantage, rendering their application in clinical testing currently difficult: nucleated erythrocytes cannot be expanded in culture, thereby ruling out metaphase chromosome analysis, an essential component of prenatal diagnosis, $\mathrm{CD} 34^{+}$cells do possess the potential for in vitro proliferation, however, they have been found to persist in the maternal circulation after delivery, thereby complicating diagnosis in consecutive pregnancies, and trophoblasts are not consistently detected in the maternal circulation. Moreover, due to the lack of a definitive fetal cell marker and a reliable sorting method, foolproof fetal cell identification of any of these cell types is not possible. ${ }^{38}$ Erythroblasts, trophoblasts, granulocytes, and lymphocytes have all been isolated by various density gradient and flow sorting techniques. The use of PCR technology on maternal blood has enabled the detection of fetal sex, Mendelian disorders (e.g. betaglobin mutations), human leukocyte antigen (HLA) polymorphisms and fetal RhD. As said before, the fetal cell type that has generated the most success is the nucleated erythrocyte. However, trophoblasts, lymphocytes and granulocytes are also considered to be present in maternal blood. Enrichment for erythroblasts and trophoblasts by various density gradient and flow sorting techniques followed by FISH with chromosomespecific DNA probes has allowed detection of chromosomal abnormalities on isolated fetal cells, such as trisomy 21 , trisomy 18, Klinefelter syndrome (KS, 47,XXY), and $47, X Y Y$. Fetal cells circulate in maternal blood during the first and second trimesters, with frequency increasing as gestation advances, and their detection is probably not affected by RhD or AB0 maternal-fetal incompatibilities. Emphasis is thus now directed toward determining the most practical and efficacious manner for this technique to be applied to prenatal genetic diagnosis. ${ }^{39,40}$

Many questions, in fact, remain about the feasibility of using fetal cells from maternal blood for prenatal diagnosis. Although recently there has been more focus on clinically relevant methods, many studies have been performed using blood drawn after invasive procedures, and over a wide range of gestational ages. For methods to be applicable to clinical use, more work is needed on isolating cells early in 
pregnancy, when termination is still an option for parents who are found to have an affected pregnancy. In fact, it has not yet been shown definitively whether there is an ideal gestational age for sampling, whether $\mathrm{AB} 0$ incompatibility might limit availability of fetal cells, or whether the number of present cells might be different in normal vs abnormal pregnancies. Polymerase chain reaction has been shown to be a powerful tool in allowing amplification and identification of very small amounts of fetal DNA. However, this is limited to cases in which a specific and unique gene from the father is sought. This means that there is the potential to diagnose many paternally inherited autosomal dominant diseases and some autosomal recessive diseases, in which the parents have different and identifiable mutations. However, when parents are both carriers of the same autosomal recessive mutations, or when the disease is X-linked, PCR will not aid in prenatal diagnosis. Cytogenetic analysis of fetal cells by FISH after cell sorting is another potentially useful method of prenatal diagnosis, but requires relatively pure samples of fetal cells or an independent marker that allows easy microscopic identification. The latter might be accomplished by identifying fetal cells through their expression of embryonic hemoglobins or because they contain HLA-G messenger RNA (mRNA). In addition, current techniques of cell sorting must be improved, so that a higher percentage of fetal cells can be isolated. Currently, the best cell sorting techniques usually produce a maximum purity of $10 \%$ fetal cells. Commonly, in normal pregnancies, fewer than $0.1 \%$ of the cells isolated after sorting are fetal in origin. Improving the concentration and quantity of fetal cells will improve the accuracy of FISH. Methods, such as immunophenotyping that allow the selective identification of fetal cells by microscopy, and can be used in conjunction with FISH, may be extremely valuable, because they may allow the genetic analysis of only the few fetal cells within a background preponderance of maternal cells. ${ }^{41}$ General PCR fails to provide adequate information from limited cells in preimplantation genetic diagnosis (PGD) and NIPD. Therefore, several whole genome amplification (WGA) techniques, such as PEP and degenerate oligonucleotide primed (DOP)-PCR, have been developed and successfully applied to clinical work during the past decade, especially in PGD and prenatal diagnosis. These techniques can provide ample amplification of genetic sequences from single cells for a series of subsequent PCR analyses, such as restriction fragment length polymorphisms (RFLP) and comparative genomic hybridization ( $\mathrm{CGH}$ ), thus opening up a new area for prenatal diagnosis. However, several problems have been reported in the application of these techniques. The ideal WGA technique should have high yield, faithful representation of the original template, complete coverage of the genome and simply performed procedure. In order to make good use of these techniques in future research and clinical work, it is undoubtedly necessary an extensive understanding of the merits and pitfalls of these recently developed techniques. ${ }^{42}$

Quantitative fluorescence (QF)-PCR has recently entered the field of prenatal diagnosis to overcome the need to culture fetal cells, hence to allow rapid diagnosis of some selected chromosomal anomalies. In the studies on the accuracy of QF-PCR in detecting chromosomal anomalies at prenatal diagnosis, the detection rate of aneuploidies of the selected chromosomes $(13,18$, and 21 , and $\mathrm{X}$ and $\mathrm{Y})$ was 98.6\% (95\% CI = 97.8-99.3). QF-PCR might play a major role and be considered a valid alternative to the full karyotype. Being less expensive, and almost entirely automated, more women could undergo invasive prenatal diagnosis without significant increase in health expenditure. By using QF-PCR as a stand-alone test, the chances of nondiagnosing the commonest, and the only chromosome anomalies which do increase in frequency with maternal age, are approximately one in 150 abnormal karyotypes, or one in 10,000-30,000 samples, based on the age distribution. These error rates might be deemed acceptable, although most structural chromosomal anomalies will be missed. At present, women are rarely informed about the full spectrum of the conditions which might be diagnosed via amniocentesis or CVS. Some of these anomalies might be acceptable, in view of their limited or uncertain clinical relevance, and decision analysis might, in the majority of cases, confine the full karyotype to selected women who have specific indications. ${ }^{43}$ However, several achievements in the field of laboratory-on-a-chip (Lab-on-a-chip) technology have provided clear advancements in projects aimed at the isolation of rare cells from biological fluids. Among the most interesting approaches are those based on dielectrophoresis (DEP). Dielectrophoresis-based Labon-a-chip platforms have been demonstrated to be suitable for several applications in biotechnology and biomedicine. Dielectrophoresis-based arrays are able to manipulate single cells, which can be identified and moved throughout the DEP chip to recovery places. Dielectrophoresis buffers are compatible with molecular interactions between monoclonal antibodies and target cells, allowing integration of these devices with MACS. Dielectrophoresis treatment does not alter the viability of manipulated cells. ${ }^{44-51}$

\section{DNA-based Prenatal Diagnosis}

DNA-based prenatal diagnosis can be performed on chorionic villi, which can be obtained as early as the 8th week of gestation. Thus, the approaches that use sensitive and specific molecular probes will allow identification of a fetus at risk 
relatively early during the pregnancy. ${ }^{52}$ The noninvasive determination of fetal genetic characteristics, including blood group types, is a long-sought goal of modern genetics. Fetal DNA is present in maternal plasma, and a proportion of such DNA is seen in intact fetal cells. Previous work on the use of fetal cells in maternal blood has been hampered by the rarity of such cells. ${ }^{53}$ The existence of high concentrations of circulating fetal DNA in maternal plasma may enable NIPD. There are many applications of fetal DNA in maternal plasma for clinical diagnosis. ${ }^{54}$ It is particularly useful that fetal DNA is present in relatively high concentrations in maternal plasma, making its robust detection possible using modern technology. ${ }^{55}$

Circulating nucleic acids are present in small amounts in the plasma of healthy individuals. However, increased levels of plasma circulating nucleic acids have been reported in a number of clinical disorders like cancer, stroke, trauma, myocardial infarction, autoimmune disorders and pregnancyassociated complications. Circulating nucleic acids have received special attention because of its potential application as a noninvasive, rapid, and sensitive tool for molecular diagnosis and monitoring of acute pathologies and the prenatal diagnosis of fetal genetic diseases. ${ }^{56}$ The detection of circulating nucleic acids has long been explored for the noninvasive diagnosis of a variety of clinical conditions. In earlier studies, detection of circulating DNA has been investigated for the detection of various forms of cancer. Metastasis and recurrence in certain cancer types have been associated with the presence of high levels of tumor-derived DNA in the circulation. In the case of pregnancies, detection of fetal DNA in maternal plasma is a useful tool for detecting and monitoring certain fetal diseases and pregnancy-associated complications. Similarly, levels of circulating DNA have been reported to be elevated in acute medical emergencies, including trauma and stroke, and have been explored as indicators of clinical severity. Apart from circulating DNA, much attention and effort have been put into the study of circulating RNA over the last few years. This area started from the detection of tumor-derived RNA in the plasma of cancer patients. Soon after that, detection of circulating fetal RNA in maternal plasma was described. Plasma RNA detection appears to be a promising approach for the development of gender and polymorphism-independent fetal markers for prenatal diagnosis and monitoring. This development also opens up the possibility of noninvasive prenatal gene expression profiling by maternal blood analysis. Besides circulating DNA and RNA in plasma and serum, cell-free DNA in other body fluids, such as urine, has been detected in patients with different clinical conditions. Regardless of the sources of cell-free DNA for clinical use, the amount is frequently scarce. Technical advancements in detecting free DNA have been made over the years. It is likely that further developments in the field of circulating nucleic acids will provide us with new diagnostic and monitoring possibilities over the next few years. ${ }^{57}$

Using molecular techniques, fetal DNA and RNA can be detected from 5 weeks gestation and are rapidly cleared from the circulation following birth. Cell-free fetal DNA comprises only 3 to $6 \%$ of the total circulating cell-free DNA, therefore diagnoses are primarily limited to those caused by paternally inherited sequences as well as conditions that can be inferred by the unique gene expression patterns in the fetus and placenta. Broadly, the potential applications of this technology fall into two categories: first, high genetic risk families with inheritable monogenic diseases, including sex determination in cases at risk of X-linked diseases and detection of specific paternally inherited single gene disorders, and second, routine antenatal care offered to all pregnant women, including prenatal screening/diagnosis for aneuploidy, particularly DS, and diagnosis of Rh-factor status in RhD-negative women. Already sex determination and Rh-factor diagnosis are nearing translation into clinical practice for high-risk individuals. ${ }^{58}$ There is more and more evidence that the trophoblastic cells act as the major source of circulating cffDNA. Contrary to fetal cells analysis in maternal blood which requires isolation and enrichment procedures, fetal DNA analysis is relatively easy to perform with the use of real-time PCR. Noninvasive fetal sex and fetal $\mathrm{RhD}$ genotype determination are, to date, the two main clinical indications. Those newly offered possibilities have changed the management of pregnant women who are carriers for X-linked genetic disorders. Prenatal diagnosis by CVS could only be performed for male fetuses avoiding an unnecessary risk of fetal loss for female fetuses. Moreover, fetal RhD genotyping by maternal blood analysis could be useful in RhD-negative women at risk of immunization in order to adapt prophylactic anti-D injection. ${ }^{59}$ The provision of prenatal diagnosis requires the highest standards in laboratory practice to ensure an accurate result. In PGD, protocols additionally have to address the need to achieve an accurate result from one to two cells within a limited time. Emerging protocols of NIPT, which are based on analysis of cffDNA in the circulation of the pregnant mother, also have to achieve a result from a limited quantity of fetal DNA against a high background of maternal free DNA. Real-time PCR uses fluorescent probes or dyes and dedicated instruments to monitor the accumulation of amplicons produced throughout the progress of a PCR reaction. Real-time PCR can be used for quantitative or qualitative evaluation of PCR products and is ideally suited for analysis of nucleotide sequence variations (point mutations) and gene dosage changes (locus deletions or insertions/duplications) that cause human 
monogenic diseases. Real-time PCR offers a means for more rapid and potentially higher throughput assays, without compromising accuracy and has several advantages over end-point PCR analysis, including the elimination of postPCR processing steps and a wide dynamic range of detection with a high degree of sensitivity. ${ }^{60}$

To date, the major use of cffDNA genotyping in the clinic has been for the noninvasive detection of the pregnancies that are at risk of hemolytic disease of the fetus and newborn (HDFN), caused by the action of maternal antibodies on paternally derived antigens present on fetal erythrocytes. The D-negative blood group is found in $15 \%$ of whites, 3 to $5 \%$ of black Africans and is rare in Asians. RhD blood group incompatibility between a pregnant woman and her fetus can result in maternal alloimmunization and consequent HDFN in subsequent pregnancies. ${ }^{61}$ This, in its most severe form, may lead to death in utero. Although the introduction of anti-D prophylaxis has greatly reduced the incidence of the disease, a significant number of cases appear each year. Prenatal diagnosis of fetal RhD status is useful for the management of $\mathrm{RhD}$-negative women with partners heterozygous for the RhD gene. Current antenatal management aims to predict whether the fetus will be severely affected, correct the fetal anemia if present, and deliver the baby at the optimal time. Indirect methods include antibody quantitation performed on maternal blood samples, and amniocentesis to determine bilirubin levels in the amniotic fluid. Fetal blood sampling offers a direct method to determine the antigen status of the fetus, and enables measurement of fetal hemoglobin and hematocrit, if appropriate. Both fetal blood sampling and amniocentesis are invasive procedures and have the potential to produce further antibody stimulation which can compound existing problems and compromise the pregnancy. The ultimate aim was then to develop an accurate, noninvasive technique for fetal DNA typing which could be carried out in the first trimester. ${ }^{62}$ The recent demonstration of the existence of cffDNA in maternal plasma and serum has opened up the possibility of determining fetal RhD status by analysis of maternal plasma or serum DNA. This possibility has recently been realized by three independent groups of investigators. This development represented an important step toward the routine application of noninvasive fetal blood group diagnosis in sensitized pregnancies and became a model for developing safer NIPT for other single-gene disorders. Pinpointing those pregnancies where further intervention is not required will reduce the demand on national health service (NHS) resources. ${ }^{63}$

Noninvasive fetal RhD genotyping, based on PCR, is an accurate and validated technique. It allows a reduction by one-third of anti-D immunoglobulin (Ig) injections to prevent $\mathrm{RhD}$ alloimmunization. In case of maternal anti-D immunization, fetal $\mathrm{RhD}$ genotyping allows to focus on $\mathrm{RhD}$ positive fetuses only the biologic and sonographic follow-up. ${ }^{64}$ Articles reporting the diagnostic accuracy of NIPD for RhD genotyping using fetal material extracted from maternal blood have been published steadily for over a decade. Healthcare providers in Europe have started to use this technology for management of the small number of sensitized pregnancies [ca. 220-600 each year in the Netherlands, Germany, France and the United Kingdom (UK)]. Scientists and clinicians are also advocating widespread implementation for the far larger number of nonsensitized RhD-negative pregnancies (ca. 34,000-125,000 each year in the same countries). Estimates of the technical performance of these tests are currently based on results from small-scale studies, together with formal meta-analysis. The issue of early assessment of test performance is one faced by many new genetic tests. Authors were found to generally present an optimistic view of NIPD, bearing in mind weaknesses identified in reporting and conduct of their studies and the analysis of results, as evidenced by the low standards for reporting of diagnostic accuracy (STARD) scores. NIPD proforma identified that specific biases were potentially introduced through selective population sampling and/or failure to report the make-up of the population tested, omission of inconclusive results, inconsistencies in the handling of repeat results on a sample, and lack of adequate controls. These factors would inevitably affect the validity of diagnostic accuracy as reported in individual publications, as well as any subsequent meta-analyses. Together, published reports to date may provide a biased picture of the actual potential of NIPD for fetal RhD genotyping. Generalization of the available evidence on diagnostic accuracy, especially to large-scale implementation of NIPD of non-sensitized women, will also require that decision makers consider further aspects, such as test reliability and cost of routine testing in clinical practice. It is recommended that all studies of diagnostic accuracy of NIPD adhere to the STARD quality checklist in order to improve reporting, thereby minimizing bias and increasing the comparability of studies. Researchers should also consider specific shortcomings for NIPD and avoid selective participant sampling, report population characteristics, report handling of replicate sampling as well as their failure rates, and include controls for genotypes tested in the study. Furthermore, meta-analyses should consider the quality, as well as the sample size, of NIPD in their analysis. Larger trials, required to produce results that are valid and meaningful for clinical practice, must also adhere to these reporting standards. ${ }^{65}$ 
In conclusion, the discovery of cell-free circulating fetal nucleic acids in maternal plasma has opened up new possibilities in NIPD. The rapid advancement of this field in the past decade is catalyzed by the discovery of new classes of fetal nucleic acid markers and technological developments in nucleic acid detection and amplification. Some of the more significant recent developments in this field include the detection of single molecule, chromosomal aneuploidies, single nucleotide variations, and placental microRNA in maternal plasma. ${ }^{66}$ NIPT of fetal chromosomal aneuploidies and monogenic diseases by analyzing fetal DNA present in maternal plasma poses a challenging goal. In particular, the presence of background maternal DNA interferes with the analysis of fetal DNA. Using single molecule counting methods, including digital PCR and MPS, many of the former problems have been solved. Digital mutation dosage assessment can detect the number of mutant alleles a fetus has inherited from its parents for fetal monogenic disease diagnosis, and plasma DNA MPS enables the direct detection of fetal chromosomal aneuploidies from maternal plasma. The analytical power of these methods, namely sensitivity, specificity, accuracy, and precision, should catalyze the eventual clinical use of NIPD. ${ }^{67-72}$

\section{Psychological Issues}

The possibility of the application of reliable NIPD to clinical practice, and its likely availability as a tool for routine antenatal screening, is an important and exciting development that will be of interest to women and couples, especially where there is a known risk arising from family history, or some other source, of having a baby with a serious, disabling, or life-limiting condition. Managing the introduction of this new technology will require attention to the understanding and perceptions of women, couples, and the wider society, as well as to the clinical, scientific, technical, and logistic issues that will inevitably arise. ${ }^{73}$ Prior to any specific prenatal diagnostic procedure, the pregnant woman should be counseled about the indications for the procedure and how the diagnosis would inform care. In addition, the risks and limitations should be clearly spelt out. The availability of NIPD, such as sonography appears to have led to a higher rate of acceptance of such procedures, especially in younger patients. The expectations of pregnant women and their partners concerning prenatal diagnosis focus on reducing uncertainty in regard to the normality of the pregnancy. However, any prenatal diagnostic procedure can cause emotional stress in the pregnant woman. There are two different types of stress in this situation. There may be anxiety about the invasive nature of the procedure and the attendant risk of the loss of a wanted pregnancy. There may also be anxiety over the outcome of the investigation. Any unexpected finding, especially an abnormal one, often has an adverse impact on the pregnant woman and her partner. Imaging of the unborn child on sonography, and revealing fetal movements and heartbeat, are increasingly a common and key experience in a pregnancy. With the advent of this now commonly shared experience, the male partner also gives up his role as a passive onlooker and becomes more actively involved in the pregnancy. Couples require multidisciplinary care if an abnormal fetus is found. ${ }^{74}$

\section{Ethical and Medicolegal Issues}

Down syndrome screening has been an integral part of routine prenatal testing for the last four decades. Assessment of risk for trisomy 21 can be carried out by a combination of maternal age, fetal NT thickness, and maternal serum free $\beta$-hCG and PAPP-A at 11 to $13^{+6}$ weeks. The patients are counseled with regards to their estimated risk, and are informed that the only way to know for sure whether or not the fetus has a chromosomal abnormality is by having an invasive test, but these tests carry a risk of miscarriage of about $1 \%$. They are also informed that although a risk of 1 in 300 or more is generally considered to be high, it is up to them to decide in favor or against invasive testing. The rate of invasive testing increases exponentially with increasing estimated risk $(r=0.917, \mathrm{P}<0.0001)$. Pregnant women are able to use sophisticated screening information to make scientifically and ethically rational decisions about invasive testing for trisomy 21. These empiric data compliment the arguments of normative ethics to create evidence-based ethical standards for informed consent regarding invasive testing. ${ }^{75}$ Recent efforts have been directed at developing additional noninvasive prenatal screening techniques that could not only improve sensitivity of prenatal screening, but also be employed in the first trimester to offer earlier diagnostic and interventional opportunities. Nuchal translucency has proven to be a cost-effective screening test that, when combined with serum markers (hCG and PAPP-A) in the first and/or second trimester, broadens the diagnostic possibilities and improves the diagnostic capabilities of current prenatal DS screening methods. Despite the potential benefits, significant operational issues regarding access to and availability of such testing may limit its widespread application and necessitates the maintenance of both non-sonographic and second trimester screening methods. The implementation of first trimester DS testing requires the development and maintenance of nationally standardized quality control systems to ensure the reliability of serum and ultrasound measurements and the accurate assessment of risk. Future efforts to improve prenatal screening should continue to emphasize the need for improved access to all aspects of prenatal care, stress the importance of provider education and 
the necessity for extensive patient counseling, and reinforce the role of patient education and choice. ${ }^{76}$

Obtaining fetal nucleic material for molecular analysis without the need of invasive procedures has been a goal of prenatal diagnosis for many years. This is now been made possible by the use of noncellular fetal nucleic acids circulating in maternal blood. The placenta is the primary source of these nucleic acids, raising the possibility that they could be a marker for pregnancy complications resulting from placental disease/dysfunction, such as preeclampsia and intrauterine growth restriction (IUGR). If so, these markers might be able to identify cases at risk, predict disease and/or its severity, or allow early diagnosis. This has the potential to allow improvements in the management of complicated pregnancies. ${ }^{77}$ Noninvasive prenatal diagnosis could significantly change the framework for testing and screening in pregnancy. The prospect of NIPD normalizing screening and termination in pregnancy is raised as a concern. Noninvasive prenatal diagnosis will also require monitoring to ensure women are making well-informed decisions, given that a risk to the pregnancy is absent. The question of whether NIPD will reduce anxiety needs to be established and the prospect that it will increase terminations on the grounds of disability should be recognized. The offer of NIPD external to any clinical oversight might give rise to wider social sex selection, paternity testing, or testing 'for information'. The value assumptions of these uses of NIPD need to be addressed. ${ }^{78}$

The traditional focus of newborn screening for inherited metabolic diseases is to test infants for medical conditions that may cause significant morbidity and mortality unless treatment is initiated early. A major change began with the application of tandem mass spectrometry to the quantitative analysis of amino acids and acylcarnitines in dried blood spots. Beyond the lack of a consensus on disease selection, the pace of introduction for expanded screening programs has been slow and patchy among and within countries. Universal metabolic screening poses important ethical issues, related to possible ambiguous findings, late-onset diseases, conditions, such as lysosomal storage disorders, with no clear-cut evidence on when and how to start a therapy. The possible application of next generation sequencing to newborn screening has been recently proposed. In the near future, it will be also possible to perform a genetic and mutational scan across the whole genome of the fetus in a noninvasive manner by analyzing cffDNA in maternal blood as early as the 5th week of gestational age. These high-throughput methods applied to neonatal and NIPT of genetic diseases, including inborn errors of metabolism, are raising further technical, political and ethical issues. ${ }^{79}$ Noninvasive prenatal diagnosis has been in clinical use for a decade. However, there is evidence that this technology will be more widely applied within the next few years. Guidance is therefore required to ensure that the procedure is offered in a way that is evidence-based and ethically and clinically acceptable. Four main themes have emerged: perceived attributes of the test, regulation and ethical issues, NIPD in practice, and economic considerations. However, there was a basic difference in the approach of actual or potential service users, who were very positive about the benefits of the technology, compared with other research participants, who were concerned with the potential moral and ethical outcomes of using this testing method. ${ }^{80,81}$

\section{Guidelines}

New developments in maternal serum and ultrasound screening have made it possible to offer all pregnant patients a noninvasive screening test to assess their risk of having a fetus with DS or trisomy 18 to determine whether invasive prenatal diagnosis tests are necessary. Invasive prenatal diagnosis would be limited to women who screen above a set risk cut-off level on noninvasive screening or pregnant women who will be 40 years at time of delivery who, after counseling, chose to go directly to amniocentesis/CVS. Currently available noninvasive screening options include maternal age combined with:

- First trimester screening (NT, maternal serum biochemical markers);

- Second trimester serum screening; or

- Two-step integrated prenatal screening (IPS), which includes first and second trimester serum screening with or without NT (IPS, serum IPS, contingent and sequential).

The quality of evidence and classification of recommendations followed discussion and consensus by the combined committees of Society of Obstetricians and Gynecologists of Canada (SOGC) (genetics, diagnostic imaging) and Canadian College of Medical Geneticists (CCMG) (prenatal diagnosis). These guidelines are intended to reduce the number of amniocenteses done when maternal age is the only indication. This will have the benefit of reducing the numbers of normal pregnancies lost because of complications of invasive procedures. Any screening test has an inherent false positive rate, which may result in undue anxiety. ${ }^{82}$ All pregnant women, regardless of age, should be offered, through an informed counseling process, the option of a prenatal screening test for the most common clinically significant fetal aneuploidies in addition to a second trimester ultrasound for dating, assessment of fetal anatomy and detection of multiples. Counseling must be nondirective and must respect a woman's right to accept or decline any or all of the testing or options offered at any point in the process. Maternal age alone is a poor minimum standard for prenatal screening for aneuploidy, and it should not be used a basis for recommending invasive testing when 
NIPT for aneuploidy is available. Invasive prenatal diagnosis for cytogenetic analysis should not be performed without multiple marker screening results except for women who are at increased risk of fetal aneuploidy:

- Because of ultrasound findings;

- Because the pregnancy was conceived by in vitro fertilization (IVF) with intracytoplasmic sperm injection (ICSI); or

- Because the woman or her partner has a history of a previous child or fetus with a chromosomal abnormality or is a carrier of a chromosome rearrangement that increases the risk of having a fetus with a chromosomal abnormality.

At minimum, any prenatal screen offered to women who present for care in the first trimester should have a detection rate of $75 \%$ with no more than a $3 \%$ false positive rate. The performance of the screen should be substantiated by annual audit. The minimum standard for women presenting in the second trimester should be a screen that has a detection rate of $75 \%$ with no more than a $5 \%$ false positive rate. The performance of the screen should be substantiated by annual audit. First trimester NT should be interpreted for risk assessment only when measured by sonographers or sonologists trained and accredited for this service and when there is ongoing quality assurance, and it should not be offered as a screen without biochemical markers in singleton pregnancies. Evaluation of the fetal nasal bone in the first trimester should not be incorporated as a screen unless it is performed by sonographers or sonologists trained and accredited for this service and there is ongoing quality assurance. For women who undertake first trimester screening, second trimester serum AFP screening and/or ultrasound examination is recommended to screen for open neural tube defects (NTD). Timely referral and access is critical for women and should be facilitated to ensure women are able to undergo the type of screening test, they have chosen as first trimester screening. The first steps of integrated screening (with or without NT), contingent, or sequential screening are performed in an early and relatively narrow time window. Ultrasound dating should be performed if menstrual or conception dating is unreliable. For any abnormal serum screen calculated on the basis of menstrual dating, an ultrasound should be done to confirm gestational age. The presence or absence of soft markers or anomalies in the 18 to 20 -week ultrasound can be used to modify the a priori risk of aneuploidy established by age or prior screening. Information, such as gestational dating, maternal weight, ethnicity, insulin-dependent diabetes mellitus (IDDM), and use of ART should be provided to the laboratory to improve accuracy of testing. Healthcare providers should be aware of the screening modalities available in their province or territory. A reliable system needs to be in place ensuring timely reporting of results. Screening programs should be implemented with resources that support audited screening and diagnostic laboratory services, ultrasound, genetic counseling services, patient and healthcare provider education, and high-quality diagnostic testing, as well as resources for administration, annual clinical audit and data management. In addition, there must be the flexibility and funding to adjust the program to new technology and protocols. ${ }^{83,84}$

The serum biochemistry and fetal NT screening (BUN) and the first and second trimester evaluation of risks (FASTER) studies, two prospective multicenter trials in the US, validated the accuracy and detection rates of first and second trimester screening previously reported abroad. These studies, coupled with the 2007 release of the American College of Obstetricians and Gynecologists (ACOG) Practice Bulletin that endorsed first trimester screening as an alternative to traditional second trimester multiple marker screening, led to an explosion of screening options available to pregnant women. American College of Obstetricians and Gynecologists also recommended that invasive diagnostic testing for chromosome aneuploidy be made available to all women regardless of maternal age. More recently, another option known as NIPT became available to screen for chromosome aneuploidy. While screening and testing options may be limited due to a variety of factors, healthcare providers need to be aware of the options in their area in order to provide their patients with accurate and reliable information. If not presented clearly, patients may feel overwhelmed at the number of choices available. ${ }^{85}$ Also an update of the consensus of the Genetics Committee of the SOGC has been published. These are its conclusions. Significant and measurable amounts of cffDNA are present in the maternal circulation and increase throughout pregnancy. Different fetal (trisomy 21, trisomy 13) and placental abnormalities can affect the levels of cffDNA within the maternal plasma. Diagnostic and screening techniques may be able to utilize this cffDNA in the future to provide noninvasive screening and diagnosis opportunities. This DNA technique is already well established for fetal sexing in pregnancies at risk of an X-linked disorder and fetal RhD evaluation. Other conditions with well-identified unique paternal mutations can also reliably apply this cffDNA technology for prenatal diagnosis. The overall use of this molecular technology is still limited and requires the identification of sex-independent DNA markers so that female fetal DNA can be distinguished from maternal DNA, allowing its use in the screening or diagnosis of fetal and placental disease in pregnancies of either fetal sex. ${ }^{86}$

Analysis of cffDNA in maternal plasma provides the opportunity for reliable, timely, safe, and cost-effective 
diagnosis of single gene disorders. The detection of certain fetal loci using cffDNA and conventional molecular analytic approaches is possible from 4 weeks gestation. To date, noninvasive first-trimester analysis for single gene disorders has been limited by assay sensitivity and specificity, due to the background maternal DNA. The anticipated ability to enrich the fetal component of cellfree DNA will increase the robustness of tests and permit semi-quantitative analysis, broadening the scope of testing to include recessive disorders, such as cystic fibrosis (CF). Testing for large-scale mutations might remain limited by the fragmented nature of cffDNA and, when testing very early in gestation, careful ultrasound examination will be needed to determine the number of gestational sacs, because of the risk of discordant twin pregnancies. ${ }^{87}$ Noninvasive prenatal testing using MPS of cffDNA to test for trisomies 21,18 , and 13 should be an option available to women at increased risk in lieu of amniocentesis. Pretest counseling of these women should include a discussion of the limitations of NIPT. No irrevocable obstetrical decision should be made in pregnancies with a positive NIPT result without confirmatory invasive diagnostic testing. Although testing of cffDNA in maternal plasma appears very promising as a screening test for DS and other trisomies, studies in averagerisk pregnancies and a significant reduction in the cost of the technology are needed before this can replace the current maternal screening approach using biochemical serum markers with or without fetal NT ultrasound. ${ }^{88}$

\section{CONCLUSION}

The invasive procedures amniocentesis and CVS are routinely applied in pregnancies at risk for fetal genetic disorders and the results obtained are the gold standard for prenatal diagnosis. These procedures have an approximately 0.5 to $1 \%$ risk for fetal loss and are mainly used in cases at risk for fetal chromosomal abnormalities and single-gene disorders. Identification of cell-free fetal nucleic acids (DNA and RNA) in maternal plasma and the recognition that they represent a useful source of fetal genetic material for prenatal diagnosis has led to intensive efforts to develop NIPT. ${ }^{89}$ In contrast to the traditional teaching that the placenta forms an impermeable barrier, multiple studies show that both intact fetal cells and cell-free nucleic acids circulate freely in maternal blood. Complications of pregnancy, such as pre-eclampsia, or fetal cytogenetic abnormalities, such as trisomy 21, increase transfusion of both intact fetal cells and cell-free fetal nucleic acids into the maternal circulation. Abnormal fetomaternal trafficking of nucleic acids is associated with fetal and placental pathology, and these observations may lead to novel noninvasive diagnostic and screening tests. Real-time quantitative PCR amplification of
DYS1, a Y-chromosome specific gene, is used as a uniquely fetal DNA marker for the development of gestation-specific normal values and theoretical models to measure the levels of male fetal DNA in case-control sets of serum or plasma taken from pregnant women. Women carrying fetuses with trisomies 21 or 13 (but not 18) have increased levels of fetal DNA in their fresh or archived serum and/or plasma samples. Women destined to develop pre-eclampsia have a characteristic biphasic elevation of cffDNA that precedes clinical symptoms. Data obtained from a variety of clinical scenarios suggest that the placenta is the predominant source of the circulating fetal nucleic acids, although apoptotic hematopoietic cells may contribute to the pool as well. Cell-free fetal DNA is elevated in a number of conditions associated with placental pathology. Widespread clinical implementation of fetal DNA as a screening tool awaits discovery of a reliable gender-independent marker, which may be DNA polymorphisms, epigenetic markers, or mRNA. Cell-free fetal nucleic acids have potential for noninvasive monitoring of placental pathology. ${ }^{90}$

Fetal DNA is present at an approximate mean fractional concentration of $10 \%$ in the plasma of pregnant women. The detection of paternally-inherited DNA sequences that are absent in the maternal genome, e.g. Y chromosomal sequences for fetal sexing and the RhD gene for blood group genotyping, is well established. The recent emergence of single molecule counting technologies, such as digital PCR and MPS has allowed circulating fetal DNA to be used for the NIPT of fetal chromosomal aneuploidies and monogenic diseases. ${ }^{91}$ Recent technical advances have led to a drastic change in the clinical applicability and potential uses of cffDNA and RNA. Genome-wide methods have been, or can be, successfully applied on total DNA (DNA-seq), methylated DNA immunoprecipitation (with tiling array), microRNA (Megaplex), and total RNA (RNA-seq). Chromosome- or gene-specific assays have been successively applied on placenta RNA (allele ratio) or DNA multiplex ligation-dependent probe amplification (MLPA). The technical advances for noninvasive aneuploidy tests based on cffDNA and placental mRNA in maternal plasma have been enormous. Multimarker assays including genome-wide approaches with the option of qualitative information on variation (polymorphism or mutation) besides quantitative information are the preferred methods of choice. The time for population-based, double blind, large-scale clinical cohort trials has come. ${ }^{92}$

Major recent advances in screening and diagnosis of non-chromosomal genetic diseases include the completion of the human genome project (HGP), the use of microarray and related technologies for mass screening and diagnosis of thousands of genetic abnormalities, and NIPT using cffDNA 
in maternal plasma. The rapid development in molecular biological technologies makes it possible to screen and to diagnose thousands of genetic conditions, mutations and also predispositions to chronic diseases or traits, either prenatally or after birth. Clinical application of NIPT using cffDNA in maternal plasma has become a reality. The arrival of the molecular genetic era also leads to many new ethical, social, and medicolegal problems and dilemmas that obstetricians will have to face in the near future. There is an urgent need for the development of a new model for provision of genetic screening and diagnosis. ${ }^{93}$ The launch of the genomics and postgenomics era has greatly expanded our understanding of the genetic basis of many diseases. In conjunction with the sociocultural trend to delay childbirth and to maintain smaller family units, extra demand may be placed on the existing prenatal diagnostic services. The inherent risk of fetal loss associated with current prenatal diagnostic procedures, such as amniocentesis and CVS, has spurred research into NIPD. Much research has been conducted on the exploitation of fetal genetic material present in the maternal circulation. The initial focus was on the isolation of intact fetal cells and subsequently, the existence of extracellular fetal DNA in maternal plasma was realized. Exciting developments have been achieved in recent years. A large-scale trial to evaluate the clinical utility of fetal cell isolation from maternal blood for fetal aneuploidy diagnosis was launched and data were recently published. Much has taken place in the research of fetal DNA analysis in maternal plasma and in one example, namely prenatal $\mathrm{RhD}$ determination, this type of analysis has been used in the clinical setting. ${ }^{94}$ Although some have wondered whether the sequencing of the human genome has led to major advances in medicine, in fact there are multiple examples where genomics has been integrated into medical practice. In the area of prevention, genomic approaches are now used for NIPT with fetal DNA in the maternal circulation, for expanded preconceptional screening for carrier status, for autosomal recessive disorders, and for assessment of risk of common disease. In the area of diagnosis, major advances have been made in cytogenomics and in use of whole exome or whole genome sequencing. In therapeutics, pharmacogenetic testing is now feasible, tumor genome sequencing is being used to guide cancer therapy, and genomic discoveries are enabling development of new targeted therapies. Ultimately, it is possible that genome sequencing may be done for all individuals on a routine basis, though there remain significant technical, ethical, and medical systems challenges to be overcome. It is likely that integration of genomics into medical practice will occur gradually over a long period of time, but the process is now well-underway. ${ }^{95-104}$

\section{REFERENCES}

1. Plouffe L Jr, Donahue J. Techniques for early diagnosis of the abnormal fetus. Clin Perinatol 1994;21(4):723-741.

2. Kramer K, Cohen HJ. Intrauterine fetal diagnosis for hematologic and other congenital disorders. Clin Lab Med 1999;19(1): 239-253, vii-viii.

3. Sybert VP, Holbrook KA. Prenatal diagnosis and screening. Dermatol Clin 1987;5(1):17-41.

4. Sekizawa A, Purwosunu Y, Matsuoka R, Koide K, Okazaki S, Farina A, Saito H, Okai T. Recent advances in noninvasive prenatal DNA diagnosis through analysis of maternal blood. J Obstet Gynaecol Res 2007;33(6):747-764.

5. Sekizawa A, Saito H. Prenatal screening of single-gene disorders from maternal blood. Am J Pharmacogenomics 2001;1(2):111-117.

6. Kang A, Hahn S, Holzgreve W. Fetal cells in maternal blood: their significance in noninvasive prenatal diagnosis and in etiologically determined diseases. Schweiz Med Wochenschr 1999;129(46):1740-1743.

7. Tsang JC, Lo YM. Circulating nucleic acids in plasma/serum. Pathology 2007;39(2):197-207.

8. Torricelli F, Pescucci C. Isolation of fetal cells from the maternal circulation: prospects for the noninvasive prenatal diagnosis. Clin Chem Lab Med 2001;39(6):494-500.

9. Chan AK, Chiu RW, Lo YM. Clinical Sciences Reviews Committee of the Association of Clinical Biochemists. Cell-free nucleic acids in plasma, serum and urine: a new tool in molecular diagnosis. Ann Clin Biochem 2003;40(Pt 2):122-130.

10. Chiu RW, Lo YM. Application of fetal DNA in maternal plasma for noninvasive prenatal diagnosis. Expert Rev Mol Diagn 2002;2(1):32-40.

11. Liao GJ, Chiu RW, Lo YM. Prenatal assessment of fetal chromosomal and genetic disorders through maternal plasma DNA analysis. Pathology 2012;44(2):69-72.

12. Dennis Lo YM, Chiu RW. Prenatal diagnosis: progress through plasma nucleic acids. Nat Rev Genet 2007;8(1):71-77.

13. Rodríguez de Alba M, Bustamante-Aragonés A, Perlado S, Trujillo-Tiebas MJ, Díaz-Recasens J, Plaza-Arranz J, Ramos C. Noninvasive prenatal diagnosis of monogenic disorders. Expert Opin Biol Ther 2012;12 Suppl 1:S171-9.

14. Wright CF, Wei Y, Higgins JP, Sagoo GS. Noninvasive prenatal diagnostic test accuracy for fetal sex using cell-free DNA a review and meta-analysis. BMC Res Notes 2012 Sep 1;5(9):476.

15. Hahn S, Zhong XY, Holzgreve W. Recent progress in noninvasive prenatal diagnosis. Semin Fetal Neonatal Med 2008;13(2):57-62.

16. Lo YM. Noninvasive prenatal diagnosis by massively parallel sequencing of maternal plasma DNA. Open Biol 2012; 2(6):120086.

17. Avent ND, Plummer ZE, Madgett TE, Maddocks DG, Soothill PW. Post-genomics studies and their application to noninvasive prenatal diagnosis. Semin Fetal Neonatal Med 2008;13(2):91-98.

18. Chitty LS, van der Schoot CE, Hahn S, Avent ND. SAFE, the special noninvasive advances in fetal and neonatal evaluation network: aims and achievements. Prenat Diagn 2008;28(2):83-88.

19. Maddocks DG, Alberry MS, Attilakos G, Madgett TE, Choi K, Soothill PW, Avent ND. The SAFE project: towards noninvasive prenatal diagnosis. Biochem Soc Trans 2009;37(Pt 2):460-465.

20. Choolani M, Narasimhan K, Kolla V, Hahn S. Proteomic technologies for prenatal diagnostics: advances and challenges ahead. Expert Rev Proteomics 2009;6(1):87-101. 
21. Cho CK, Diamandis EP. Application of proteomics to prenatal screening and diagnosis for aneuploidies. Clin Chem Lab Med 2011;49(1):33-41.

22. Alldred SK, Deeks JJ, Guo B, Neilson JP, Alfirevic Z. Second trimester serum tests for Down's syndrome screening. Cochrane Database Syst Rev 2012;6:CD009925.

23. Schmid W. Noninvasive screening for chromosome abnormalities in young pregnant patients. Arch Gynecol Obstet 1992;252 Suppl:S36-43.

24. Snijders RJ, Noble P, Sebire N, Souka A, Nicolaides KH. UK multicentre project on assessment of risk of trisomy 21 by maternal age and fetal nuchal-translucency thickness at 10-14 weeks of gestation. Fetal Medicine Foundation First Trimester Screening Group. Lancet 1998;352(9125):343-346.

25. Borruto F, Comparetto C, Acanfora L, Bertini G, Rubaltelli FF. Role of ultrasound evaluation of nuchal translucency in prenatal diagnosis. Clin Exp Obstet Gynecol 2002;29(4):235-241.

26. Getz L, Kirkengen AL. Ultrasound screening in pregnancy: advancing technology, soft markers for fetal chromosomal aberrations, and unacknowledged ethical dilemmas. Soc Sci Med 2003;56(10):2045-2057.

27. Colmant C, Morin-Surroca M, Fuchs F, Fernandez H, Senat MV. Noninvasive prenatal testing for fetal sex determination: is ultrasound still relevant? Eur J Obstet Gynecol Reprod Biol 2013 Sep 11. pii: S0301-2115(13)00455-457.

28. Odibo AO, Ghidini A. Role of the second-trimester 'genetic sonogram' for Down syndrome screen in the era of first-trimester screening and noninvasive prenatal testing. Prenat Diagn 2014 Jan 16.

29. Maymon R, Jauniaux E. Down's syndrome screening in pregnancies after assisted reproductive techniques: an update. Reprod Biomed Online 2002;4(3):285-293.

30. Bischoff FZ, Sinacori MK, Dang DD, Marquez-Do D, Horne C, Lewis DE, Simpson JL. Cell-free fetal DNA and intact fetal cells in maternal blood circulation: implications for first and second trimester noninvasive prenatal diagnosis. Hum Reprod Update 2002;8(6):493-500.

31. Lim JH, Park SY, Ryu HM. Noninvasive prenatal diagnosis of fetal trisomy 21 using cell-free fetal DNA in maternal blood. Obstet Gynecol Sci 2013;56(2):58-66.

32. Adinolfi M, Sherlock J. Fetal cells in transcervical samples at an early stage of gestation. J Hum Genet 2001;46(3):99-104.

33. Miller D, Briggs J. Reliability of trans-cervical recovery of placental cells from the lower uterine pole using a minimally invasive procedure. Evidence based on fetal sexing and analysis of recovered cell populations. Early Hum Dev 1996;47 Suppl:S99-102.

34. Holzgreve W, Hahn S. Fetal cells in cervical mucus and maternal blood. Baillieres Best Pract Res Clin Obstet Gynaecol 2000;14(4):709-722.

35. Siffroi JP, Freiss-Rouas N, Kanafani S, Menier C. Fetal cells in the maternal blood and prenatal diagnosis. Gynecol Obstet Fertil 2000;28(11):785-791.

36. Bianchi DW. Fetal cells in the mother: from genetic diagnosis to diseases associated with fetal cell microchimerism. Eur J Obstet Gynecol Reprod Biol 2000;92(1):103-108.

37. O’Donoghue K, Chan J. Human fetal mesenchymal stem cells. Curr Stem Cell Res Ther 2006;1(3):371-386

38. Guetta E, Simchen MJ, Mammon-Daviko K, Gordon D, AviramGoldring A, Rauchbach N, Barkai G. Analysis of fetal blood cells in the maternal circulation: challenges, ongoing efforts, and potential solutions. Stem Cells Dev 2004;13(1):93-99.

39. Simpson JL, Elias S. Isolating fetal cells in maternal circulation for prenatal diagnosis. Prenat Diagn 1994;14(13):1229-1242.

40. Simpson JL, Elias S. Isolating fetal cells in the maternal circulation. Hum Reprod Update 1995;1(4):409-418.

41. Steele CD, Wapner RJ, Smith JB, Haynes MK, Jackson LG. Prenatal diagnosis using fetal cells isolated from maternal peripheral blood: a review. Clin Obstet Gynecol 1996;39(4):801-813.

42. Peng W, Takabayashi H, Ikawa K. Whole genome amplification from single cells in preimplantation genetic diagnosis and prenatal diagnosis. Eur J Obstet Gynecol Reprod Biol 2007;131(1):13-20.

43. Nicolini U, Lalatta F, Natacci F, Curcio C, Bui TH. The introduction of QF-PCR in prenatal diagnosis of fetal aneuploidies: time for reconsideration. Hum Reprod Update 2004;10(6):541-548.

44. Borgatti M, Bianchi N, Mancini I, Feriotto G, Gambari R. New trends in noninvasive prenatal diagnosis: applications of dielectrophoresis-based Lab-on-a-chip platforms to the identification and manipulation of rare cells. Int J Mol Med 2008;21(1):3-12.

45. Kavanagh DM, Kersaudy-Kerhoas M, Dhariwal RS, Desmulliez MP. Current and emerging techniques of fetal cell separation from maternal blood. J Chromatogr B Analyt Technol Biomed Life Sci 2010;878(22):1905-1911.

46. Huang Z, Fong CY, Gauthaman K, Sukumar P, Choolani M, Bongso A. Novel approaches to manipulating foetal cells in the maternal circulation for noninvasive prenatal diagnosis of the unborn child. J Cell Biochem 2011;112(6):1475-1485.

47. Lichtenbelt KD, Knoers NV, Schuring-Blom GH. From karyotyping to array-CGH in prenatal diagnosis. Cytogenet Genome Res 2011;135(3-4):241-250.

48. Hillman SC, McMullan DJ, Williams D, Maher ER, Kilby MD. Microarray comparative genomic hybridization in prenatal diagnosis: a review. Ultrasound Obstet Gynecol 2012;40(4): 385-391.

49. Rosner M, Hengstschläger M. Amniotic fluid stem cells and fetal cell microchimerism. Trends Mol Med 2013;19(5):271-272.

50. Hillman SC, McMullan DJ, Hall G, Togneri FS, James N, Maher EJ, Meller CH, Williams D, Wapner RJ, Maher ER, Kilby MD. Use of prenatal chromosomal microarray: prospective cohort study and systematic review and meta-analysis. Ultrasound Obstet Gynecol 2013;41(6):610-620.

51. Hatt L, Brinch M, Singh R, Møller K, Lauridsen RH, Uldbjerg N, Huppertz B, Christensen B, Kølvraa S. Characterization of fetal cells from the maternal circulation by microarray gene expression analysis - could the extravillous trophoblasts be a target for future cell-based noninvasive prenatal diagnosis? Fetal Diagn Ther 2014;35:218-227.

52. Christiano AM, Uitto J. DNA-based prenatal diagnosis of heritable skin diseases. Arch Dermatol 1993;129(11):1455-1459.

53. Poon LL, Leung TN, Lau TK, Lo YM. Prenatal detection of fetal Down's syndrome from maternal plasma. Lancet 2000;356(9244):1819-1820.

54. Poon LL, Lo YM. Circulating fetal DNA in maternal plasma. Clin Chim Acta 2001;313(1-2):151-155.

55. Lo YM. Fetal DNA in maternal plasma: application to noninvasive blood group genotyping of the fetus. Transfus Clin Biol 2001;8(3):306-310. 
56. Swarup V, Rajeswari MR. Circulating (cell-free) nucleic acids - A promising, noninvasive tool for early detection of several human diseases. FEBS Lett 2007;581(5):795-799.

57. Tong YK, Lo YM. Diagnostic developments involving cell-free (circulating) nucleic acids. Clin Chim Acta 2006;363(1-2):187-196.

58. Wright CF, Burton H. The use of cell-free fetal nucleic acids in maternal blood for noninvasive prenatal diagnosis. Hum Reprod Update 2009;15(1):139-151.

59. Costa JM, Gautier E, Benachi A. Genetic analysis of the fetus using maternal blood. Gynecol Obstet Fertil 2004;32(7-8):646-650.

60. Traeger-Synodinos J. Real-time PCR for prenatal and preimplantation genetic diagnosis of monogenic diseases. Mol Aspects Med 2006;27(2-3):176-191.

61. van der Schoot CE, Hahn S, Chitty LS. Noninvasive prenatal diagnosis and determination of fetal Rh status. Semin Fetal Neonatal Med 2008;13(2):63-68.

62. Shields JA. Prenatal typing of fetal DNA in cases of potential alloimmune haemolytic disease of the newborn: clinical benefit outweighs disadvantage. Br J Biomed Sci 1999;56(1):49-55.

63. Lo YM. Fetal RhD genotyping from maternal plasma. Ann Med 1999;31(5):308-312.

64. Carbonne B, Cortey A, Rouillac-Le Sciellour C, Brossard Y. Noninvasive fetal RhD genotyping using maternal blood: time for use in all $\mathrm{RhD}$ negative pregnant women. Gynecol Obstet Fertil 2008;36(2):200-203.

65. Freeman K, Szczepura A, Osipenko L. Noninvasive fetal RHD genotyping tests: a systematic review of the quality of reporting of diagnostic accuracy in published studies. Eur J Obstet Gynecol Reprod Biol 2009;142(2):91-98.

66. Hung EC, Chiu RW, Lo YM. Detection of circulating fetal nucleic acids: a review of methods and applications. J Clin Pathol 2009;62(4):308-313.

67. Chiu RW, Cantor CR, Lo YM. Noninvasive prenatal diagnosis by single molecule counting technologies. Trends Genet 2009;25(7):324-331.

68. Avent ND, Chitty LS. Noninvasive diagnosis of fetal sex; utilisation of free fetal DNA in maternal plasma and ultrasound. Prenat Diagn 2006;26(7):598-603.

69. Hall A, Bostanci A, Wright CF. Noninvasive prenatal diagnosis using cell-free fetal DNA technology: applications and implications. Public Health Genomics 2010;13(4):246-255.

70. Chiu RW, Lo YM. Noninvasive prenatal diagnosis by fetal nucleic acid analysis in maternal plasma: the coming of age. Semin Fetal Neonatal Med 2011;16(2):88-93.

71. Hill M, Barrett AN, White H, Chitty LS. Uses of cell free fetal DNA in maternal circulation. Best Pract Res Clin Obstet Gynaecol 2012;26(5):639-654.

72. Borruto F, Treisser A, Abdelkrim SB, Comparetto C. The end of amniocentesis? From TriTest to PrenaTest ${ }^{\mathrm{TM}}$. Donald School J Ultrasound Obstet Gynecol 2013;7(2):213-218.

73. Kent A. Noninvasive prenatal diagnosis: public and patient perceptions. Semin Fetal Neonatal Med 2008;13(2):109-112.

74. Kowalcek I. Stress and anxiety associated with prenatal diagnosis. Best Pract Res Clin Obstet Gynaecol 2007;21(2):221-228.

75. Nicolaides KH, Chervenak FA, McCullough LB, Avgidou K, Papageorghiou A. Evidence-based obstetric ethics and informed decision-making by pregnant women about invasive diagnosis after first-trimester assessment of risk for trisomy 21. Am J Obstet Gynecol 2005;193(2):322-326.

76. Fuchs KM, Peipert JF. First trimester Down syndrome screening: public health implications. Semin Perinatol 2005;29(4):267-271.
77. Alberry MS, Soothill PW. Noninvasive prenatal diagnosis: implications for antenatal diagnosis and management of highrisk pregnancies. Semin Fetal Neonatal Med 2008;13(2):84-90.

78. Newson AJ. Ethical aspects arising from noninvasive fetal diagnosis. Semin Fetal Neonatal Med 2008;13(2):103-108.

79. Scala I, Parenti G, Andria G. Universal screening for inherited metabolic diseases in the neonate (and the fetus). J Matern Fetal Neonatal Med 2012;25(Suppl 5):4-6.

80. Skirton H, Patch C. Factors affecting the clinical use of noninvasive prenatal testing: a mixed methods systematic review. Prenat Diagn 2013;33(6):532-541.

81. Smith RP, Lombaard H, Soothill PW. The obstetrician's view: ethical and societal implications of noninvasive prenatal diagnosis. Prenat Diagn 2006;26(7):631-634.

82. Summers AM, Langlois S, Wyatt P, Wilson RD. Society of Obstetricians and Gynaecologists of Canada. Prenatal screening for fetal aneuploidy. J Obstet Gynaecol Can 2007;29(2):146-179.

83. Chitayat D, Langlois S, Wilson RD. Genetics Committee of the Society of Obstetricians and Gynaecologists of Canada; Prenatal Diagnosis Committee of the Canadian College of Medical Geneticists. Prenatal screening for fetal aneuploidy in singleton pregnancies. J Obstet Gynaecol Can 2011;33(7):736-750.

84. Audibert F, Gagnon A. Genetics Committee of the Society of Obstetricians and Gynaecologists of Canada; Prenatal Diagnosis Committee of the Canadian College of Medical Geneticists. Prenatal screening for and diagnosis of aneuploidy in twin pregnancies. J Obstet Gynaecol Can 2011;33(7):754-767.

85. Wilson KL, Czerwinski JL, Hoskovec JM, Noblin SJ, Sullivan CM, Harbison A, Campion MW, Devary K, Devers P, Singletary CN. NSGC practice guideline: prenatal screening and diagnostic testing options for chromosome aneuploidy. J Genet Couns 2013;22(1):4-15.

86. Wilson RD. Genetics Committee of the SOGC. Cell-free fetal DNA in the maternal circulation and its future uses in obstetrics. J Obstet Gynaecol Can 2005;27(1):54-62.

87. Norbury G, Norbury CJ. Noninvasive prenatal diagnosis of single gene disorders: how close are we? Semin Fetal Neonatal Med 2008;13(2):76-83.

88. Langlois S, Brock JA, Wilson RD, Audibert F, Brock JA, Carroll J, Cartier L, Gagnon A, Johnson JA, Langlois S, et al. Current status in noninvasive prenatal detection of down syndrome, trisomy 18, and trisomy 13 using cell-free DNA in maternal plasma. J Obstet Gynaecol Can 2013;35(2):177-181.

89. Vaiopoulos AG, Athanasoula KC, Papantoniou N, Kolialexi A. Review: advances in noninvasive prenatal diagnosis. In Vivo 2013;27(2):165-170.

90. Bianchi DW. Circulating fetal DNA: its origin and diagnostic potential - a review. Placenta 2004;25 Suppl A:S93-S101.

91. Lo YM. Fetal nucleic acids in maternal blood: the promises. Clin Chem Lab Med 2012;50(6):995-998.

92. Go AT, van Vugt JM, Oudejans CB. Noninvasive aneuploidy detection using free fetal DNA and RNA in maternal plasma: recent progress and future possibilities. Hum Reprod Update 2011;17(3):372-382.

93. Lau TK, Leung TN. Genetic screening and diagnosis. Curr Opin Obstet Gynecol 2005;17(2):163-169.

94. Chiu RW, Lo YM. Noninvasive prenatal diagnosis: on the horizon. Pharmacogenomics 2003;4(2):191-200.

95. Korf BR. Integration of genomics into medical practice. Discov Med 2013;16(89):241-248. 
96. Faas BH, Cirigliano V, Bui TH. Rapid methods for targeted prenatal diagnosis of common chromosome aneuploidies. Semin Fetal Neonatal Med 2011;16(2):81-87.

97. Collins SL, Impey L. Prenatal diagnosis: types and techniques. Early Hum Dev 2012;88(1):3-8.

98. Bustamante-Aragonés A, Rodríguez de Alba M, Perlado S, Trujillo-Tiebas MJ, Arranz JP, Díaz-Recasens J, Troyano-Luque J, Ramos C. Noninvasive prenatal diagnosis of single-gene disorders from maternal blood. Gene 2012;504(1):144-149.

99. Simpson JL. Invasive procedures for prenatal diagnosis: any future left? Best Pract Res Clin Obstet Gynaecol 2012;26(5):625-638.

100. How Kit A, Nielsen HM, Tost J. DNA methylation based biomarkers: practical considerations and applications. Biochimie 2012;94(11):2314-2337.
101. Twiss P, Hill M, Daley R, Chitty LS. Noninvasive prenatal testing for Down syndrome. Semin Fetal Neonatal Med 2013 Nov 6. pii: S1744-165X(13)00095-4.

102. Babkina N, Graham JM Jr. New genetic testing in prenatal diagnosis. Semin Fetal Neonatal Med 2013 Dec 3. pii: S1744165X(13)00097-8.

103. Petersen O, Vogel I, Ekelund C, Hyett J, Tabor A. Potential diagnostic consequences of applying noninvasive prenatal testing (NIPT): a population-based study from a country with existing first trimester screening. Ultrasound Obstet Gynecol 2014;43(3):265-271.

104. Haymon L, Simi E, Moyer K, Aufox S, Ouyang DW. Clinical implementation of noninvasive prenatal testing among maternal fetal medicine specialists. Prenat Diagn 2014 May;34(5): 416-423. 